\title{
Palliative care in neuro-oncology
}

We are so pleased to introduce this series of the Annals of Palliative Medicine about Palliative Care in Neuro-Oncology. Patients with primary or metastatic tumors affecting the nervous system present a tremendous and sometimes overwhelming array of challenges in all aspects of palliative care. Patients and their caregivers face symptoms and side effects from neurosurgical, radiation, chemotherapy and neurological issues, requiring a coordinated effort from all these disciplines, and specialist centers are mainly concentrated in large urban areas, leaving a huge population of patients deprived of multidisciplinary specialty care. Fortunately, palliative care providers are uniquely enabled and prepared to address the wide spectrum of issues that may arise across the time from initial diagnosis through treatment and its complications, neurologic decline and bereavement.

This series focuses on a broad range of topics in neuro-oncology including oncological management, death and dignity, mental health, care-giver bereavement, and religious/spiritual concerns. We are so grateful for our many colleagues across disciplines who assist our patients (and ourselves) in providing this care. Many of them are represented in this series (and we only wish there was room for more!): like the articles from neurologists Dr. Sharma and Drs. Ironside and Perry on prognostication and management of gliomas; radiation oncologists Drs Nguyen and Soliman, Drs. Chow, Drs. Lo and Tseng, and Drs. Vellayappan and Sahgal on the benefits and consequences of radiation therapy; and the psychologists, psychiatrists, social workers and chaplains like Drs. Gibson, Korman, Ellis, Fitchett, Isenberg-Grzeda, Morris, Nurse Practitioner Claire Moroney, and LCSW Sofie who guide our patients and families to manage distress and find meaning and dignity when facing and surviving their disease.

We trust these articles, from the many perspectives represented, will help guide our patients and families, and ourselves, as we all work and hope together to improve care for neuro-oncology patients and their caregivers.

\section{Acknowledgments}

Funding: None.

\section{Footnote}

Provenance and Peer Review: This article was commissioned by the editorial office, Annals of Palliative Medicine for the series "Palliative Care in Neuro-Oncology". The article did not undergo external peer review.

Conflicts of Interest: Both authors have completed the ICMJE uniform disclosure form (available at http://dx.doi.org/10.21037/ apm-2019-pcno-12). The series "Palliative Care in Neuro-Oncology" was commissioned by the editorial office without any funding or sponsorship. JJG and HS served as the unpaid Guest Editors of the series. The authors have no other conflicts of interest to declare.

Ethical Statement: The authors are accountable for all aspects of the work in ensuring that questions related to the accuracy or integrity of any part of the work are appropriately investigated and resolved.

Open Access Statement: This is an Open Access article distributed in accordance with the Creative Commons AttributionNonCommercial-NoDerivs 4.0 International License (CC BY-NC-ND 4.0), which permits the non-commercial replication and distribution of the article with the strict proviso that no changes or edits are made and the original work is properly cited (including links to both the formal publication through the relevant DOI and the license). See: https://creativecommons.org/licenses/by-nc$\mathrm{nd} / 4.0 \%$. 


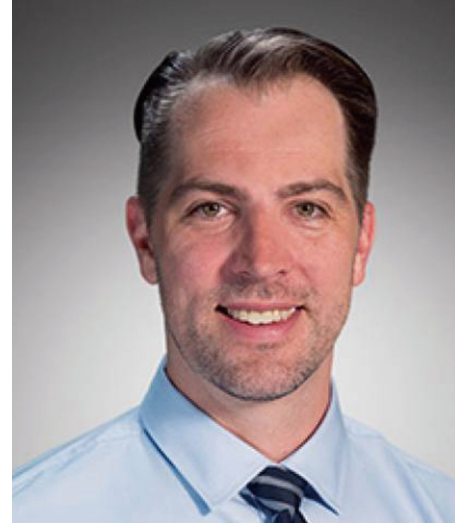

Jerome J. Graber

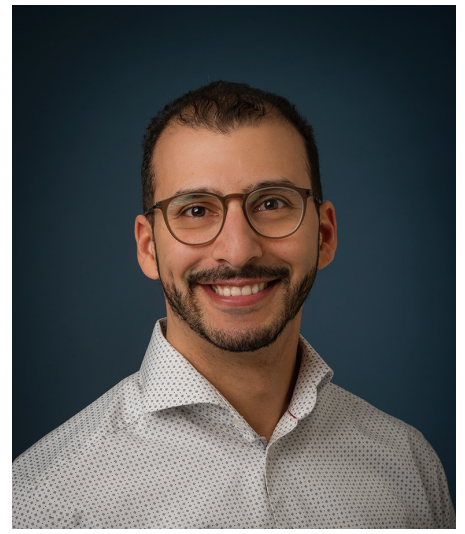

Hany Soliman

Jerome J. Graber, MD, MPH.

Associate Professor of Neurology and Neurosurgery, University of Washington, Seattle Cancer Care Alliance, Alvord Brain Tumor Center, Seattle, Washington, USA.

(Email:jgraber@uw.edu)

Hany Soliman, MD, FRCPC.

Assistant Professor, Department of Radiation Oncology, University of Toronto, Sunnybrook Odette Cancer Center, Toronto, Canada.

(Email: Hany.soliman@sunnybrook.ca)

Submitted Nov 25, 2020. Accepted for publication Dec 23, 2020. doi: 10.21037/apm-2019-pcno-12

View this article at: http://dx.doi.org/10.21037/apm-2019-pcno-12

Cite this article as: Graber JJ, Soliman H. Palliative care in neuro-oncology. Ann Palliat Med 2021;10(1):836-837. doi: 10.21037/apm-2019-pcno-12 